\title{
Dark adaptation in patients with Best vitelliform macular dystrophy
}

\author{
Wendy Baca, Gerald A Fishman, Kenneth R Alexander, Andrew M Glenn
}

\begin{abstract}
Psychophysical dark adaptation studies were performed in six patients with Best vitelliform macular dystrophy (BVMD) using a Goldmann-Weekers dark adaptometer. Prebleach thresholds were determined before obtaining a postbleach full recovery curve. Unlike patients with Stargardt macular dystrophy, all patients with BVMD showed a normal time to reach their baseline dark adapted thresholds after bleaching of their rod visual pigment when tested in clinically normal appearing retina. Although a lipofuscin material accumulates within retinal pigment epithelial cells in patients with either Best or Stargardt dystrophy, functional findings pertaining to recovery of rod dark adaptation thresholds as well as electro-oculogram light peak to dark trough ratios are different in these two disorders.
\end{abstract}

(Br F Ophthalmol 1994; 78: 430-432)

Best vitelliform macular dystrophy (BVMD) is an autosomal dominant macular degeneration with variable expression. It probably involves primarily a disorder of the retinal pigment epithelium. ${ }^{1-3}$

Stargardt disease, another juvenile onset macular dystrophy, is transmitted as an autosomal recessive trait and also involves impairment of retinal pigment epithelial cells. In both Stargardt and Best dystrophies, the accumulation of lipofuscin or a lipofuscin-like material, has been demonstrated in the retinal pigment epithelium. ${ }^{1-5}$

Since patients with Stargardt disease can show a prolongation of rod dark adaptation, ${ }^{67}$ particularly if prebleach dark adapted thresholds are obtained, we analysed dark adaptation in six patients with BVMD to determine whether these patients also had abnormalities in dark adaptation. Unlike previous investigations of dark adaptation testing in patients with Best dystrophy, ${ }^{8-13}$ we obtained prebleach dark adapted thresholds before determining the time course of rod dark adaptation.

\section{Materials and methods}

Six patients with BVMD were selected from the files of one of the authors (GAF). Inclusion criteria were an abnormally low light peak to dark trough ratio on electro-oculographic (EOG) testing, macular lesions consistent with recognisable phenotypes reported as occurring in BVMD, and at least one family member with BVMD. The study patients included four males and two females ranging in age from 12 to 67 years (mean 39.0 years; median 38 years). Patients 4 and 5 are siblings, and patients 2 and 3 are mother and daughter.

All patients underwent a complete ophthalmic assessment that included the determination of best corrected Snellen visual acuity; slit-lamp examination of the anterior segment, lens, and vitreous; and a dilated fundus examination. No ocular abnormalities were noted except for changès consistent with BVMD. No patient was receiving drugs known to affect vision, and none had a general disorder likely to cause visual loss, such as diabetes. Two patients (patients 2 and 3 , Table 1) complained of a delay in the ability to adjust to a darkened environment after at least a moderate degree of exposure to light; the remaining four patients did not.

Visual field measurements were obtained with a Goldmann perimeter. Three patients (patients 1 to 3 , Table 1) had various degrees of central scotomas with the II-e-2 and II-e-4 test targets while the others had no central scotomas to these test targets.

Control data from a previous study on dark adaptation were used. ${ }^{6}$ Eight subjects (four men and four women) were used as controls, all of whom had normal ocular examination findings with visual acuity correctable to at least 20/20. The control group included staff personnel, students, and the spouse of one of the authors. The subjects' ages ranged from 23 to 43 years
Department of Ophthalmology and Visual Sciences, University of Illinois at Chicago College of Medicine, Chicago, Illinois, USA W Baca

G A Fishman

K R Alexander

A M Glenn

Correspondence to: Gerald A Fishman, MD, UIC Eye Center, University of W Taylor St, Chicago, IL 60612, USA.

Accepted for publication 10 January 1994
Table 1 Dark adaptation findings

\begin{tabular}{|c|c|c|c|c|}
\hline $\begin{array}{l}\text { Patient } \mathrm{No} / \\
\text { age (years)/sex }\end{array}$ & $\begin{array}{l}\text { Dark adapted rod prebleach } \\
\text { thresholds (log units) }\end{array}$ & $\begin{array}{l}\text { Cone plateau thresholds } \\
\text { (log units) }\end{array}$ & $\begin{array}{l}\text { Cone-rod break time } \\
\text { (min) }\end{array}$ & $\begin{array}{l}\text { Time to reach prebleach } \\
\text { threshold }(\min )^{\star}\end{array}$ \\
\hline $\begin{array}{l}1 / 67 / M \\
2 / 32 / \mathrm{F} \\
3 / 65 / \mathrm{F} \\
4 / 12 / \mathrm{M} \\
5 / 14 / \mathrm{M} \\
6 / 44 / \mathrm{M}\end{array}$ & $\begin{array}{l}2 \cdot 1 \\
2 \cdot 0 \\
2 \cdot 3 \\
1.5 \\
1.9 \\
1.9\end{array}$ & $\begin{array}{l}5 \cdot 4 \\
t \\
5 \cdot 0 \\
4 \cdot 8 \\
4 \cdot 4 \\
5 \cdot 0\end{array}$ & $\begin{array}{l}11 \\
t \\
14 \cdot 5 \\
10 \\
8 \\
6.5\end{array}$ & $\begin{array}{l}31 \\
27 \\
37 \cdot 5 \\
25 \\
35 \\
28\end{array}$ \\
\hline $\begin{array}{l}\text { Patient: } \\
\text { Mean }\end{array}$ & $2 \cdot 0$ & 4.9 & 10 & \\
\hline Range & $1 \cdot 5-2 \cdot 3$ & $4 \cdot 4-5 \cdot 4$ & $6 \cdot 5-14 \cdot 5$ & $\begin{array}{l}30 \cdot 0 \\
25-37 \cdot 5\end{array}$ \\
\hline $\begin{array}{c}\text { Control: } \\
\text { Mean } \\
\text { Range }\end{array}$ & $\begin{array}{l}1 \cdot 8 \\
1 \cdot 7-2 \cdot 0\end{array}$ & $\begin{array}{l}5 \cdot 1 \\
4 \cdot 6-5 \cdot 5\end{array}$ & $\begin{array}{l}9 \cdot 6 \\
7 \cdot 3-12 \cdot 2\end{array}$ & $\begin{array}{l}31 \cdot 4 \\
27-39\end{array}$ \\
\hline
\end{tabular}

^Time to reach within $0.2 \mathrm{log}$ units of the prebleach threshold. fCould not be determined accurately. 
(mean $28 \cdot 1$ years). At the time of testing, none of these control subjects was receiving medication that might influence psychophysical test results.

\section{Method}

Measurement of dark adaptation was performed by two of the authors (WB and AMG) using a Goldmann-Weekers dark adaptometer. The pupil of the tested eye was dilated to 7 to $8 \mathrm{~mm}$ with $1 \%$ tropicamide drops. The left eye was tested in all patients except patient 3 , whose visual acuity was markedly better in the right eye. The tested eye was dark adapted for 1 hour. Prebleach baseline threshold measurements were then obtained at four retinal loci $\left(20^{\circ}\right.$ and $30^{\circ}$ superior and inferior to a dim red fixation light). Thresholds were measured with a $2^{\circ}$ circular test target that flickered at $0.5 \mathrm{~Hz}$. The test stimulus was either long wavelength ('orange' cut off filter with $90^{\circ}$ transmission at $555 \mathrm{~nm}$; Corning 3482, Corning, NY, USA) or short wavelength ('blue' band pass filter with a transmission peak at approximately $460 \mathrm{~nm}$; Corning 4305). The two stimuli were presented alternately and thresholds for each chromatic stimulus were measured with the method of limits, using both ascending and descending trials. The subject pressed a buzzer to indicate detection and disappearance of the test light. The threshold for each chromatic stimulus was defined as the mean of the ascending and descending trials.

From the four retinal loci tested, a final test locus was chosen that was within the range of normal or closest to normal. The baseline threshold at the chosen test locus was defined as the mean of three threshold measurements with the blue test stimulus. Thresholds were then measured at $5^{\circ}$ on either side of the test locus to verify that thresholds at these locations were comparable with those at the test locus, so that if slight variations in fixation occurred, thresholds were being measured at loci with equivalent threshold values.

Subjects were allowed to adapt to room illumination for 3 minutes, and then the tested eye was exposed for 5 minutes to an adapting field of $3 \cdot 1 \log \mathrm{cd} \mathrm{m}^{-2}$, provided by the Goldmann-Weekers adaptometer. Subjects were monitored during bleaching to ensure that the eye was kept fully open during the full bleaching period. Following the bleach, thresholds were measured at the chosen test locus until they returned to within $0.2 \mathrm{log}$ units of the prebleach value. At the end of dark adaptation, thresholds were again measured at $5^{\circ}$ on either side of the test locus to establish that they were comparable to those obtained before the bleach. Pupil size was also remeasured to confirm the maintenance of maximal dilatation throughout the testing period.

\section{Results}

Table 1 shows the age, sex, dark adapted rod prebleach thresholds, cone plateau thresholds, cone-rod break time, and time to reach the prebleach threshold for the six BVMD patients. Cone thresholds were defined as the mean of two

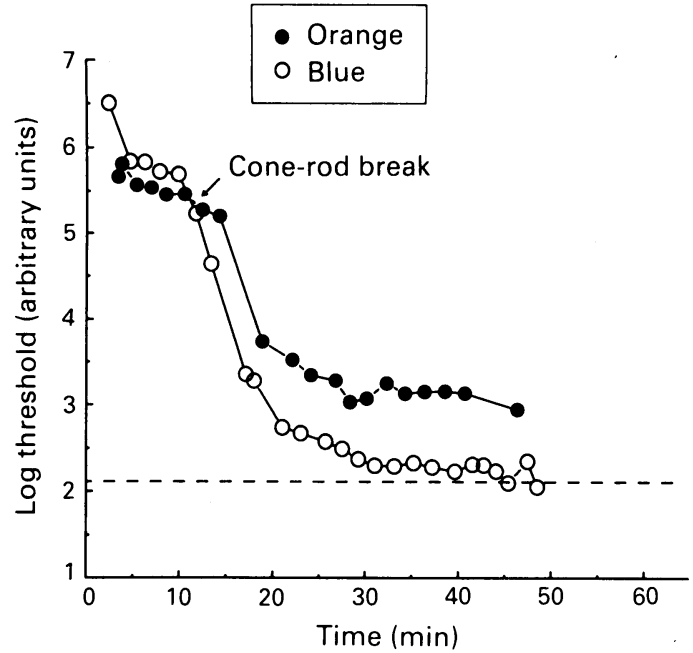

Figure 1 Representative dark adaptation curve of patient 1 with Best vitelliform macular dystrophy (Table 1) depicting a normal cone-rod break time (arrow) and normal recovery to prebleach rod threshold values (broken line)

to four measurements at the end of the cone plateau for the orange test stimulus. We defined the cone-rod break time as the time at which the threshold curve for the blue stimulus crossed the curve for the orange stimulus. Also shown in Table 1 are the means and ranges for eight normal eyes tested at $20^{\circ}$ superior to fixation.

For all BVMD patients, the time to reach the prebleach rod threshold was within normal limits. In four BVMD patients, prebleach thresholds were within the normal range while in two patients, over the age of 60 years, the thresholds were slightly beyond the upper range of our younger control subjects whose ages ranged from 23 to 43 years. The cone plateau thresholds were within the range of normal for five patients. For the sixth patient (patient 2, Table 1) the cone plateau threshold could not be determined accurately because of an inconsistency in data points during this time period. For four patients, the cone-rod break time was within normal limits, while for patient 3, the cone-rod break time was slightly prolonged. In patient 2 , the cone-rod break time could not be determined with certainty because an inconsistency in data points surrounding the cone-rod break time. A dark adaptation curve from a representative

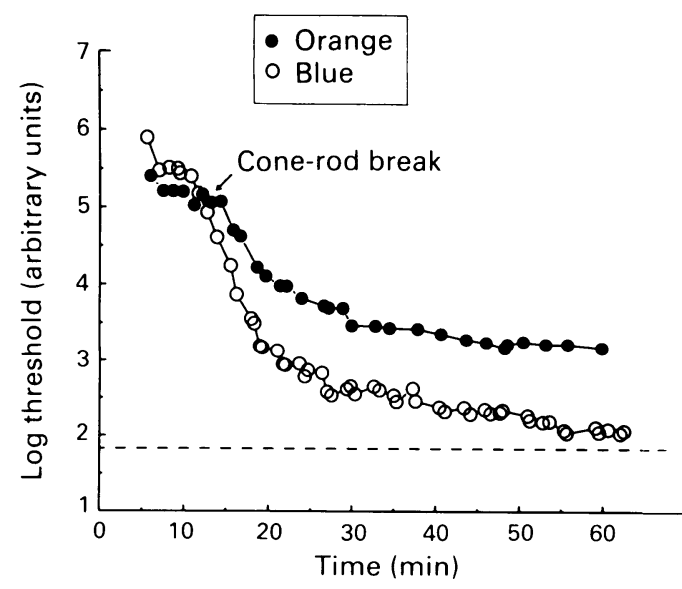

Figure 2 Representative dark adaptation curve from a patient with Stargardt disease demonstrating a normal conerod break time (arrow) but prolonged recovery to prebleach rod threshold values (broken line). 
BVMD patient (patient 1, Table 1 ) is shown in Figure 1. For comparison, a dark adaptation curve from a patient with Stargardt dystrophy showing a delayed recovery time to the prebleach threshold, is shown in Figure 2. Measurements were made with the same procedure and protocol as used for patients with BVMD. This patient had characteristic atrophic appearing macular lesions and yellowish-white fundus flecks.

\section{Discussion}

Previous studies of dark adaptation in patients with BVMD did not obtain prebleach thresholds and did not determine the rate of recovery to prebleach thresholds. Without determining a prebleach baseline threshold, it could be difficult to ascertain accurately a delay in threshold recovery. For example, by first determining a prebleach threshold, Alexander and Fishman were able to demonstrate a prolonged rod dark adaptation in some patients with retinitis pigmentosa. ${ }^{14}$ Also by using this procedure, delays in rod dark adaptation were demonstrated in patients with Stargardt disease. ${ }^{6}$

In the present study, prebleach thresholds were obtained on BVMD patients in order to establish a baseline, and rates of recovery to these prebleach thresholds were determined. After a bleach of their visual pigment, full dark adaptation curves for all six of our patients returned to prebleach values within a normal time. In addition, with consideration of their age in two patients, we found normal rod dark adapted thresholds in our BVMD patients, as did other investigators. ${ }^{8-11}$ Also like these investigators, we did not find a lengthening of the cone-rod break time to be a feature of this disorder, unlike Braley and Spivey ${ }^{12}$ and Sorsby et $a l,{ }^{13}$ who did observe a prolonged cone-rod break time.

Patients with Stargardt disease and those with BVMD share a similar histopathological finding. In both macular dystrophies, an accumulation of lipofuscin or a lipofuscin-like material in all retinal pigment epithelial cells has been demonstrated. ${ }^{1-5}$ The significance of the accumulation of this material to retinal pigment epithelial cell function is uncertain. In theory, this lipofuscin material could result in a mechanical impediment to the transport of nutrient materials to the retinal photoreceptors, as well as in a compromise of the transport of 11-cis-retinal between the retinal pigment epithelium and photoreceptors, causing possible abnormalities in dark adaptation. In fact, in patients with Stargardt disease, rod dark adaptation has been found to be abnormally delayed. ${ }^{6}$
In BVMD patients, however, rod dark adaptation is normal despite the presence of a lipofuscinlike pigment accumulation. This finding provides a further distinction between these two disorders, in addition to differences in EOG responses. EOG light peak to dark trough ratios are often normal in patients with Stargardt disease, while abnormal EOG ratios are, by definition, diagnostic of BVMD.

In our study, dark adaptation testing was performed only at retinal loci outside vitelliform lesions, in regions with normal or near normal absolute thresholds. Further studies are needed to determine whether normal rod dark adaptation recovery times will also be obtained in areas of the retina with ophthalmoscopically evident vitelliform lesions, since prolonged regeneration of foveal cone visual pigment has been shown by fundus reflectometry in at least some patients with Best vitelliform macular disease. ${ }^{15}$

Supported by core grant EY01792 and research grant EY08301 from the National Eye Institute, National Institutes of Health, Bethesda, Maryland, USA, and by a centre grant from the National RP Foundation Fighting Blindness, Baltimore, Maryland, USA.

1 O'Gorman S, Flaherty WA, Fishman GA, Berson EL. Histopathologic findings in Best's vitelliform macular dystrophy. Arch Ophthalmol 1988; 106: 1261-8.

2 Weingeist TA, Kobrin JL, Watzke RC. Histopathology of Best's macular dystrophy. Arch Ophthalmol 1982; 100: 1108-14.

3 Frangieh GT, Green WR, Fine SL. A histopathologic study of Best's macular dystrophy. Arch Ophthalmol 1982; 100: 1115-21.

4 Eagle RC Jr, Lucier AC, Bernardino VB Jr, Yanoff M. Retinal pigment epithelial abnormalities in fundus flavimaculatus: a pigment epithelial abnormalities in fundus flavimaculatus: a
light and electron microscopic study. Ophthalmology 1980; 87: 1189-200.

5 Lopez PF, Maumenee IH, de la Cruz Z, Green WR Autosomal-dominant fundus flavimaculatus: clinico-
pathologic correlation. Ophthalmology 1990; 97: 798-809.

6 Fishman GA, Farbman JS, Alexander KR. Delayed rod dark adaptation in patients with Stargardt's disease. Ophthalmology 1991; 98: 957-62.

7 Klien BA, Krill AE. Fundus flavimaculatus: clinical, functional and histopathologic observations. Am $\mathcal{f}$ Ophthalmo $1967 ; 64: 3-23$.

8 Francois J, DeRouck A, Fernandez-Sasso D. Electrooculography in vitelliform degeneration of the macula. Arch Ophthalmol 1967; 77: 726-33.

9 Krill AE, Morse PA, Potts AM, Klien BA. Hereditary vitelliruptive macular degeneration. Am f Ophthalmol 1966; 61: 1405-15.

10 Deutman AF. The hereditary dystrophies of the posterior pole of the eye. Springfield, IL: Charles C Thomas, 1971: 237.

11 Schwartz LJ, Metz HS, Woodward F. Electrophysiologic and fluorescein studies in vitelliform macular degeneration. Arch fluorescein studies in vitelliform

12 Braley AE, Spivey BE. Hereditary vitelline macular degeneration: a clinical and functional evaluation of a new pedigree with variable expressivity and dominant inheritance. Arch Ophthalmol 1964; 72: 743-62.

13 Sorsby A, Savory M, Davey JB, Fraser RJL. Macular cysts: a dominantly inherited affection with a progressive course. BrF Ophthalmol 1956; 40: 144-58.

14 Alexander KR, Fishman GA. Prolonged rod dark adaptation in retinitis pigmentosa. Br $\mathcal{F}$ Ophthalmol 1984; 68: 561-9.

15 Van Meel GJ, Van Norren D. Foveal densitometry as a diagnostic technique in Stargardt's disease. Am $\mathscr{f}$
Ophthalmol 1986; 102: $353-62$. 